\title{
T cell-selective deletion of Oct1 protects animals from autoimmune neuroinflammation while maintaining neurotropic pathogen response
}

\author{
Heejoo Kim ${ }^{1,2+}$, Laura Dickey ${ }^{1 \dagger}$, Colleen Stone ${ }^{1}$, Jillian L. Jafek ${ }^{1,2}$, Thomas E. Lane ${ }^{1 *}$ and Dean Tantin ${ }^{1,2^{*}}$ (I)
}

\begin{abstract}
Background: Treatments for autoimmune diseases aim to dampen autoreactivity while preserving normal immune function. In $\mathrm{CD}^{+}{ }^{\mathrm{T}}$ cells, the transcription factor Oct1/Pou2f1 is a dispensable transcription factor for T cell development and response to primary infection, but promotes expression of target genes, including $/ 12$ and Ifng, under conditions of antigen reencounter. As a result, they are more strongly expressed upon secondary stimulation. Such repeated antigen encounters occur in memory recall responses, in autoimmunity where self-antigen can be recognized multiple times, and in chronic infection where foreign antigen is persistent. Based on these previous findings, we hypothesized that Oct1 loss would protect animals from autoimmunity but maintain normal responses to pathogens in the CNS.

Objective: We used a conditional mouse Oct1 (Pou2f1) allele and a CD4-Cre driver to determine the effect of T cellspecific Oct1 loss on autoimmune- and viral-induced neuroinflammation using an autoantigen-driven EAE model of autoimmunity and a JHMV model of viral infection.

Results: Oct1 conditional deletion mitigated clinical scores and reduced infiltrating $T$ cells and cytokine production in the EAE model. Consistently, Oct1-deficient CD4 ${ }^{+} \mathrm{T}$ cells stimulated in vitro showed increased expression of markers associated with T cell anergy, particularly in the absence of co-stimulatory signals. In contrast, anti-viral T cell effector functions are intact in the absence of Oct1, with no changes in neuroinflammation, infiltrating T cells or cytokine production.

Conclusion: Our findings uncover a significant difference between the effect of Oct1 loss on autoimmune and antipathogen responses, which potentially could be exploited for therapeutic benefit.
\end{abstract}

Keywords: Oct1/POU2F1, T lymphocytes, Experimental autoimmune encephalomyelitis, JHMV

\section{Introduction}

Multiple sclerosis (MS) is a chronic debilitating neurological disease characterized by inflammation, demyelination, and neuronal damage caused by the inappropriate response of the host immune system towards cells of the central nervous system (CNS) [1]. Although the pathophysiology of MS is not entirely understood, active MS lesions are characterized by CNS infiltration by both

\footnotetext{
* Correspondence: tom.lane@path.utah.edu; dean.tantin@path.utah.edu ${ }^{+}$Heejoo Kim and Laura Dickey contributed equally to this work.

${ }^{1}$ Department of Pathology, University of Utah School of Medicine, Salt Lake City, UT 84112, USA

Full list of author information is available at the end of the article
}

$\mathrm{CD}^{+} \mathrm{T}$ cells-arranged around the periphery of active MS lesions-and $\mathrm{CD}^{+} \mathrm{T}$ cells (typically perivascular), with the subsequent activation of microglial cells, macrophages, and B cells [2]. CD4 ${ }^{+} \mathrm{T}$ cells can be thought of as master regulators of the immune response during MS, whereas perivascular $\mathrm{CD}^{+} \mathrm{T}$ cells, microglial cells, macrophages, and even neutrophils largely mediate white matter damage [2]. Genome-wide association studies (GWAS) pinpoint the major histocompatibility complex (MHC) genes located in the human leukocyte antigen (HLA) region as having the strongest influence on disease, further emphasizing the importance of $\mathrm{T}$ cells in MS pathophysiology [3]. 
Oct1/Pou2f1 is a POU-domain transcription factor that in mice is dispensable for $\mathrm{T}$ cell development and response to primary infection but is important for the formation of $\mathrm{CD}_{4}^{+}$central memory cells [4]. Consequently, $\mathrm{CD}^{+}{ }^{+} \mathrm{T}$ cells lacking Oct1 are completely defective in memory recall responses. Memory $\mathrm{T}$ cells are highly prone to making proinflammatory cytokines, and memory or memory-like cells can underlie autoimmunity (including T1D), even in cases of persistent selfantigen exposure [5-7]. In vitro, Oct1 and its cofactor OCA-B coordinately control a large cohort of critical direct target genes in $\mathrm{CD} 4^{+}$lymphocytes, including $\mathrm{Il2}$, Il21, Stat5a, Ifng, Tbx21 (Tbet), Csf2 (Gmcsf), Tnfrsf4 (Ox40), Icos, and Ctla4 [4]. Interestingly, Oct1 and OCA-B are dispensable for the baseline activity of these genes. For example, $\mathrm{CD} 4^{+} \mathrm{T}$ cells lacking Oct1 due to germline or conditional deletion develop normally and express normal levels of the key $\mathrm{T}$ cell effector cytokine gene IL-2 upon primary stimulation $[4,8]$. Instead, Oct1 and OCA-B strongly regulate these genes under conditions of antigen re-encounter such that secondary stimulation of resting but previously activated cells results in expression defects of 20-fold or more [8]. During $\mathrm{CD} 4^{+}$ $\mathrm{T}$ cell polarization, Oct1 works together with another transcription factor, CTCF, to mediate physical communication between the Il4, Ifng, and Il17a target loci [9]. The Oct1 cofactor OCA-B/Bob.1 has also been linked to $\mathrm{CD}^{+}{ }^{+}$central memory cell formation and function and to the formation of Th17 cells $[4,10]$. Cumulatively, the findings point to a potent role of Oct1 and OCA-B in the control of $\mathrm{CD} 4^{+} \mathrm{T}$ cell responses, but only under specific circumstances involving repeated antigen exposure. This normal development and stimulation response forms part of a potential "therapeutic window" in which targeting Oct1 and its associated pathways could be used to treat autoimmune responses while sparing normal immune function.

In addition to immune memory, repeated antigen encounter also occurs in situations such as chronic infection, graft-versus-host disease, tumor immunity, and autoimmunity. In the case of the latter, human GWAS studies show strong associations between polymorphisms in binding sites for Oct1 and predisposition for autoimmune disease including rheumatoid arthritis, celiac disease, type-1 diabetes, ulcerative colitis, autoimmune thyroiditis, and MS [11-14]. The strong associations with processes governing neuroinflammatory disease, and MS in particular, lead us to consider the role of Oct1 in neuroinflammatory $\mathrm{T}$ cell responses to autoantigens and viral infection.

Here, we show that Oct1 loss in T cells greatly attenuates clinical responses, $\mathrm{T}$ cell infiltration, and cytokine production in a murine experimental autoimmune encephalomyelitis (EAE) model, while maintaining immune responses to JHMV infection. EAE is auto-antigen-driven and is the prototypic mouse model of MS. The decreased clinical responsiveness was associated with changes in the expression of anergy-associated surface proteins on $\mathrm{CD} 4^{+} \mathrm{T}$ cells upon stimulation in vitro, in particular in the absence of costimulatory signals. Using a model of neuroinflammation induced by intracranial infection by the neurotropic JHM strain of mouse hepatitis virus (JHMV), we observed few differences in clinical scores, infiltrating $\mathrm{T}$ cells and macrophages and cytokine expression. Viral clearance was slowed but complete in animals with Oct1-deficient $\mathrm{T}$ cells. Cumulatively, these results suggest that targeting pathways involving Oct1 in $\mathrm{CD}^{+} \mathrm{T}$ cells may provide a novel therapeutic avenue for the treatment of MS and other neuroinflammatory diseases, while largely sparing beneficial immune function.

\section{Material and methods Laboratory mice}

All mice used in this study were on the C57BL/6 J strain background. Oct1 (Pou2f1) conditional mice crossed to CD4-Cre have been previously described [4]. All animal experiments were approved by the University of Utah Institutional Animal Care and Use Committee (17-05008).

\section{Induction and scoring of EAE}

EAE was initiated using a myosin oligodendrocyte protein (MOG)/Bordetella pertussis toxin (PT) method [15]. Briefly, mice were subcutaneously injected with $0.2 \mu \mathrm{mol}$ of MOG $_{35-55}$ peptide (MEVGWYRSPFSRVVHLYRNGK, synthesized at the University of Utah HSC Core) in complete Freund's adjuvant (CFA, Sigma, $2 \mathrm{mg} / \mathrm{mL}$ ). Two hundred nanograms of PT (Sigma) was injected into the mice twice intravenously. Clinical scores were determined based on the following criteria: 0 , no clinical disease; 1 , loss of tail tonicity; 2 , mild hind limb paresis; 3 , moderate hind limb paralysis; 4 , paraplegia; 5 , quadriplegia, coma, or death. For tissue analysis, animals were sacrificed at peak disease (days 20-21).

\section{Leukocyte isolation and intracellular cytokine staining}

Leukocytes were isolated from spinal cords and cervical lymph nodes using a Percoll gradient method [16-18]. Briefly, tissues were dissociated by grinding and passed through a nylon strainer. Cells were centrifuged with $80 \%$ and $40 \%$ Percoll at $1300 \times g$ at room temperature. Cells at the interface between 40 and $80 \%$ Percoll were taken. For intracellular staining, isolated cells were stimulated with PMA (Sigma, $50 \mathrm{ng} / \mathrm{mL}$ ) and ionomycin (Sigma, $1 \mu \mathrm{g} / \mathrm{mL}$ ) along with brefeldin A (Golgi Plug, Becton-Dickenson) for $4 \mathrm{~h}$ and were fixed with cell fixation/permeabilization solution (BD Cytofix/Cytoperm ${ }^{\mathrm{tm}}$ ) according to manufacturer's protocol. Antibodies used for flow cytometry were as follows: FITC conjugated anti-mouse CD4 (Biolegend), PerCP 
conjugated anti-mouse CD8a, APC-conjugated anti-mouse IFNY, and PE-conjugated anti-mouse IL-17 (eBioscience).

\section{In vitro culture}

Spleens were harvested from CD4-Cre;Oct $1^{f l f l}$ and control CD4-Cre animals 10 days after inoculation with $\mathrm{MOG}_{35-55}$ peptide and CFA. Single-cell suspensions were prepared by grinding spleens through $70-\mu \mathrm{m}$ strainers. $\mathrm{CD}^{+} \mathrm{T}$ cells were isolated by a mouse $\mathrm{CD} 4^{+} \mathrm{T}$ cell isolation kit (Miltenyi Biotec). The isolated $\mathrm{CD} 4^{+}$ $\mathrm{T}$ cells were cultured as described previously [8] and stimulated with $5 \mu \mathrm{g} / \mathrm{ml}$ plate-bound anti-CD3e (BD Bioscience) and $2 \mu \mathrm{g} / \mathrm{ml}$ anti-CD28 antibodies (eBioscience) for $24 \mathrm{~h}$.

\section{JHMV}

For intracranial (i.c.) injections, age-matched (5-7 weeks) C57BL/6 mice of different genotypes were anesthetized with an intraperitoneal (i.p.) injection of $200 \mu \mathrm{L}$ of a mixture of ketamine (Hospira, Lake Forest, IL, USA) and xylazine (Phoenix Pharmaceutical, Saint Joseph, MO, USA) in Hank's balanced salt solution (HBSS). Mice were injected i.c. with 200 plaque-forming units (PFU) of JHMV (strain V34) suspended in $30 \mu \mathrm{L}$ HBSS. Clinical severity was assessed using a previously described 4-point scoring scale [19]. For analysis of viral titers, mice were sacrificed at indicated time points. One half of each brain was homogenized and used in a plaque assay performed using the DBT mouse astrocytoma cell line [19].

\section{Cell isolation and flow cytometry}

Immunophenotyping of immune cells present within brains and spinal cords of JHMV-infected mice at defined times post-infection (p.i.) was accomplished by homogenizing isolated tissue and generating single-cell suspensions for analysis by flow cytometry using previously described procedures [19-21]. In brief, isolated cells were stained with the following antibodies: APCconjugated rat anti-mouse $\mathrm{CD} 4$ and a PE-conjugated tetramer specific for the CD4 immunodominant epitope present within the JHMV matrix (M) glycoprotein spanning amino acids 133-147 (M133-147 tetramer) to determine total and virus-specific $\mathrm{CD} 4^{+}$cells, respectively [19-21]; APC-conjugated rat anti-mouse CD8a and a PE-conjugated tetramer specific for the CD8 immunodominant epitope present in the spike (S) glycoprotein spanning amino acids 510-518 (S510518) to identify total and virus-specific $\mathrm{CD}^{+}$cells, respectively [19-21]. Tetramers were synthesized by the NIH tetramer core facility: APC-conjugated rat anti-mouse CD4 and PEconjugated anti-CD25 to determine total T-regulatory cells and BV510-conjugated rat anti-mouse CD45 and FITC-conjugated anti-F4/80 to identify macrophages.
Samples were analyzed using a BD LSR Fortessa X-20 flow cytometer and FlowJo software.

\section{Histology}

Spinal cords were isolated at defined time points and fixed overnight with $4 \%$ paraformaldehyde at $4{ }^{\circ} \mathrm{C}$. Sections were subsequently cryoprotected in $30 \%$ sucrose for 5-7 days, separated into 12 coronal sections and embedded in optimum cutting temperature (OCT) formulation (VWR, Radnor, PA, USA) [15, 19-21]. Coronal sections $(8-\mu \mathrm{m}$ thick) were cut, and sections were stained with luxol fast blue (LFB) in combination with hematoxylin and eosin (H\&E). Areas of total white matter and demyelinated white matter were determined with Image J Software. The percent demyelination was calculated by dividing the area of demyelinated white matter by the total white matter area using established methods previously described [19].

\section{Statistical analysis}

All error bars denote \pm SEM. Student $t$ tests were used to ascribe statistical significance. For all figures, ${ }^{*}=p$ value $\leq 0.05$ and $* *=p$ value $\leq 0.01$.

\section{Results}

To determine the effects of Oct1 in T cells on the pathogenesis of a neuroautoimmune disease, we used Oct1 $\mathrm{T}$ cell conditional mice (CD4-Cre;Oct $f^{f l f l}[4]$ and control mice $\left(O c t 1^{f l f l}\right)$ in conjunction with a MOG-EAE model of MS. Following inoculation with peptide corresponding to myelin oligodendrocyte glycoprotein MOG $_{35-55}$, see methods) and with Freund's complete adjuvant, pertussis toxin was injected into mice to increase bloodbrain barrier permeability. Disease severity was determined by evaluating the clinical score. C57BL/6 mice develop clinical symptoms 9-14 days after MOG injection [22]. As shown in Fig. 1a, CD4-Cre;Oct ${ }^{f l f l}$ mice were significantly protected, with clinical scores less than 1, while the control Oct $1^{f l / f l}$ mice exhibited much higher clinical involvement at the peak point of disease (day 20, Fig. 1a). Additionally, we collected spinal cords for histopathological scoring 21 days after EAE induction. The degree of demyelination in control mice was doubled to that of the CD4-Cre;Oct ${ }^{f l / f l}$ group (Fig. 1b, c). These results reveal that Oct1 deletion in $\mathrm{T}$ cells strongly protects mice from clinical symptoms in a MOG-EAE model of MS.

$\mathrm{T}$ cells are indispensable for the pathogenesis of EAE and MS [23]. IFNY and IL-17 expression in CNSinfiltrating Th1 and Th17 $\mathrm{CD}^{+} \mathrm{T}$ cells in EAE correlates with clinical severity [23-25]. Both $\mathrm{CD}^{+}$and $\mathrm{CD}^{+} \mathrm{T}$ cells contribute to clinical and histologic disease. $\mathrm{CD}^{+} \mathrm{T}$ cells are recruited to lesions and mediate the destruction of oligodendrocytes and axons [26, 27]. 


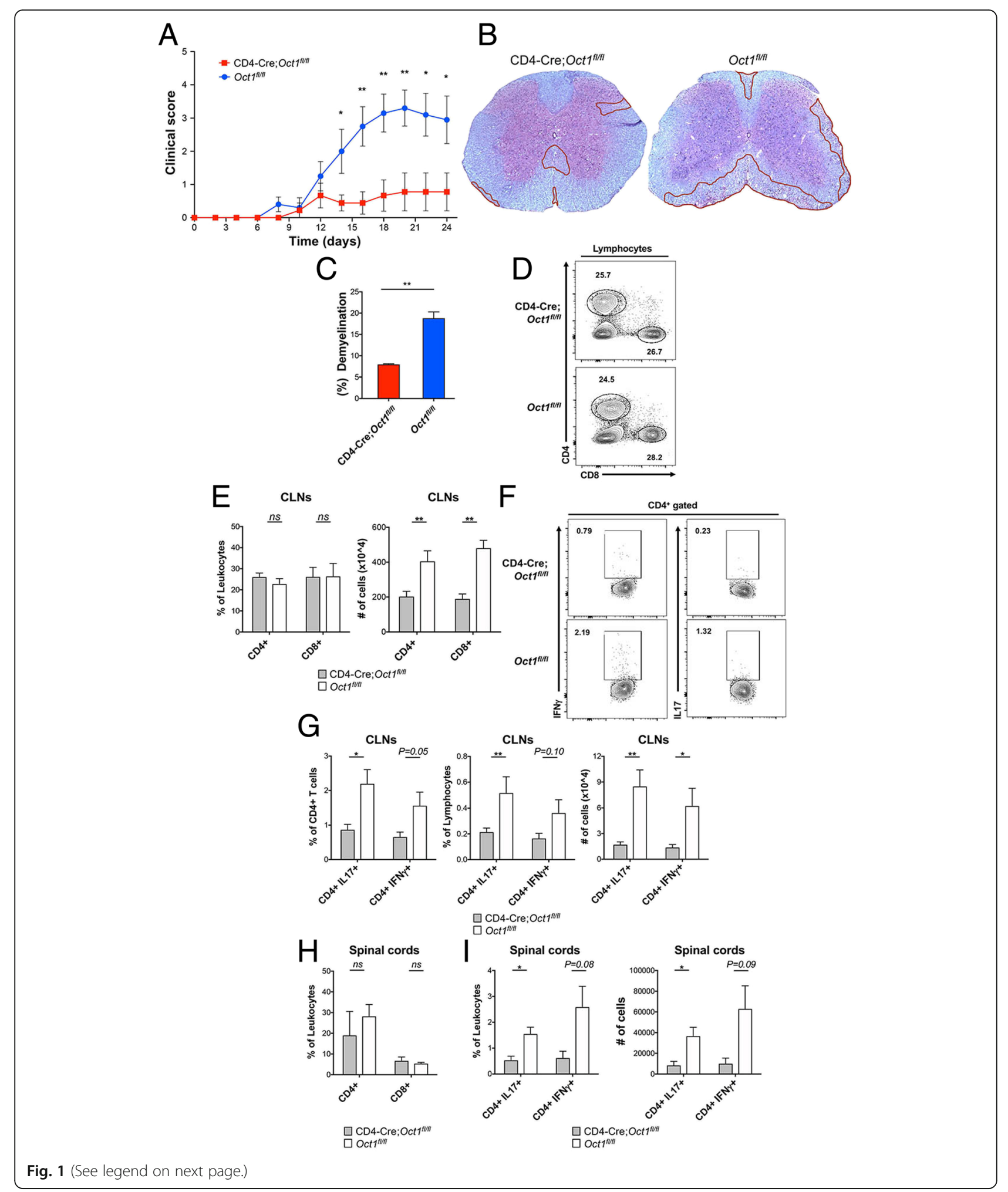


(See figure on previous page.)

Fig. 1 Loss of Oct1 in T cells protects mice using an EAE model of MS. a CD4-Cre;Oct $7^{f / f f l}(n=9)$ or Oct $7^{f / f f}(n=10)$ mice were injected with $M_{35}$-55 peptide and pertussis toxin to generate EAE. Clinical scores were determined during the post-treatment timecourse. $\mathbf{b}$ Representative LFB staining of thoracic spinal cord sections from animals taken at peak disease (day 21). Areas of demyelination are outlined in red. c Quantification of demyelination in experimental mice. Mean \% demyelination from six sections of two mice. $\mathbf{d}$ Cervical lymph node lymphocytes were isolated from EAE-induced CD4-Cre;Oct $7^{f / f f}(n=6)$ or Oct $7^{f / f f l}(n=6)$ mice and analyzed by flow cytometry. Frequencies of CD4 and CD8 cells from representative animals are shown. e Mean $\mathrm{CD} 4^{+}$and $\mathrm{CD} 8^{+} \mathrm{T}$ cell percentages (left panel) and total cell numbers (right panel). Cells were independently purified from the CLNs of six separate six mice. $\mathbf{f}$ Representative data showing frequencies of cytokine-producing CD4 ${ }^{+}$cells in the CLN. g Percentages (left and middle panels) or total cell numbers (right panel) of cytokine-producing CD4 ${ }^{+} \mathrm{T}$ cells are plotted. $N=6$ for each group. Mean of results is shown. $\mathbf{h}$ Mean $\mathrm{CD}^{+}$and $\mathrm{CD}^{+} \mathrm{T}$ cell percentages in the spinal cords. $\mathrm{N}=3-4$ for each group. $\mathbf{i}$ Cytokine-producing $\mathrm{CD}^{+} \mathrm{T}$ cell percentages (left panel) and total cell numbers (right panel). Cells were independently purified from the spinal cords of separate six mice

Therefore, we screened $\mathrm{T}$ cell populations in the draining cervical lymph nodes (CLNs) and in the spinal cords of Oct1 conditional and control mice at the peak of disease progression to determine if $\mathrm{T}$ cells lacking Oct1 have reduced autoimmune activity in the CNS and CLNs. Although the percentages of $\mathrm{CLN} \mathrm{CD} 4^{+}$and $\mathrm{CD}^{+}$were similar between the groups (Fig. 1d, e left panel), fewer $(p<0.01)$ total $\mathrm{CD}^{+}$and $\mathrm{CD}^{+} \mathrm{T}$ cells were detected in the CD4-Cre;Oct $f^{f l / f l}$ group compared to control Oct $1^{f l / f l}$ mice (Fig. 1e, right panel). This result is suggestive of reduced lymph node cellularity in the EAE model. Because $\mathrm{CD} 4^{+} \mathrm{T}$ cells are the primary inducers in EAE models [23], we also profiled cytokine production in these cells. Both frequencies and total numbers of IL-17- and IFN $\gamma$-producing $\mathrm{CD}^{+}{ }^{+} \mathrm{T}$ cells were reduced in the CLNs of CD4-Cre;Oct ${ }^{f l f l}$ mice compared to Oct $1^{f l / f l}$ controls (Fig. 1f, g). As with CLNs, frequencies of $\mathrm{CD}^{+}$and $\mathrm{CD} 8^{+} \mathrm{T}$ cells were similar in the spinal cords of CD4-Cre;Oct $f^{f l f l}$ and Oct $1^{f l f l}$ mice (Fig. 1h). Total numbers of $\mathrm{CD} 4^{+}$and $\mathrm{CD}^{+}{ }^{+} \mathrm{T}$ cells were also similar between CD4-Cre;Oct1 $1^{f l / f l}$ and Oct1 $1^{f l f l}$ mice (not shown). However, as in the CLNs, proinflammatory cytokine production was strongly reduced in the infiltrating $\mathrm{T}$ cells in the spinal cords of CD4-Cre;Oct $f^{f l / f l}$ mice compared to controls (Fig. 1i). These data indicate that loss of Oct1 in $\mathrm{T}$ cells strongly protects animals from clinical symptoms of EAE and that this protection is associated with decreased CNS T cell proinflammatory cytokine expression.

$\mathrm{T}$ cell anergy is a peripheral tolerance mechanism induced by TCR stimulation in the absence of costimulatory signals, in which $\mathrm{T}$ cells become poorly reactive, protecting animals from potential autoreactivity [2831]. Oct1 loss results in decreased expression of target genes such as Ifng, selectively in the context of repeated $\mathrm{T}$ cell stimulation [8]. Gene expression profiling using $\mathrm{CD} 4^{+}$ $\mathrm{T}$ cells deficient in the Oct1 cofactor OCA-B reveals not only that these genes are downregulated, but also identifies increases in the expression of genes associated with anergy, e.g., Ctla4 [4]. Anergic responses can be modeled in vitro by providing $\mathrm{T}$ cells with primary TCR simulation (via immobilized anti-CD3e monoclonal antibodies) in the absence of co-stimulation [31]. To determine the effect of Oct1 loss on anergic responses, we harvested $\mathrm{CD} 44^{+} \mathrm{CD} 44^{+}$ $\mathrm{T}$ cells (consisting mostly of pre-activated resting cells) from the spleens of CD4-Cre;Oct $f^{f l / f l}$ and control Oct $\mathrm{P}^{f l / f l}$ animals, restimulated them for $24 \mathrm{~h}$ ex vivo using antiCD3 antibodies with or without CD28 co-stimulation, and profiled the expression of proteins associated with activation and anergy.

ICOS (inducible $\mathrm{T}$ cell costimulator) has an important but complex role in the induction of $\mathrm{T}$ cell anergy in vitro and the development of autoimmunity in vivo [3234]. Analyzing ICOS expression by flow cytometry, we found that baseline ICOS levels were $\sim 2$-fold higher in naïve Oct1-deficient cells but that no differences were apparent in fully stimulated cells receiving anti-CD3/28 (Fig. 2a, b). Interestingly, stimulating Oct1-deficient cells with anti-CD3 alone resulted in significantly reduced ICOS expression in Oct1-deficient cells compared to the control group (Fig. 2a, b). Both the increased baseline ICOS expression in resting cells and decreased expression upon anergic stimulation are consistent with the observed protection in an EAE model, as ICOS blockade during antigen priming (days 1-10) increases brain inflammation and promotes EAE, whereas blockade later in EAE pathogenesis (days 9-20) decreases CNS leukocyte infiltration and is protective [33, 35]. Additionally, the expression of CD25, the high-affinity IL-2 receptor induced upon $\mathrm{CD} 4^{+} \mathrm{T}$ cell activation [36], was decreased in Oct1-deficient cells specifically in anergic conditions lacking co-stimulation. $\mathrm{T}$ regulatory cells (Tregs) express CD25 and also produce IL-10; however, IL-10 production in these cells was similar to control CD4+ $\mathrm{T}$ cells (Additional file 1), indicating that these in vitro differences are associated with effector $\mathrm{T}$ cells. In contrast to CD25, CD44 expression levels were similar between the groups (Fig. 2c, d). These results show that ICOS and CD25 levels are altered in Oct1-deficient cells in a manner consistent with observed protection in the EAE model.

We also analyzed the expression of inhibitory molecules correlated with anergic responses. The expression of CTLA4, a checkpoint inhibitor and an anergy marker 

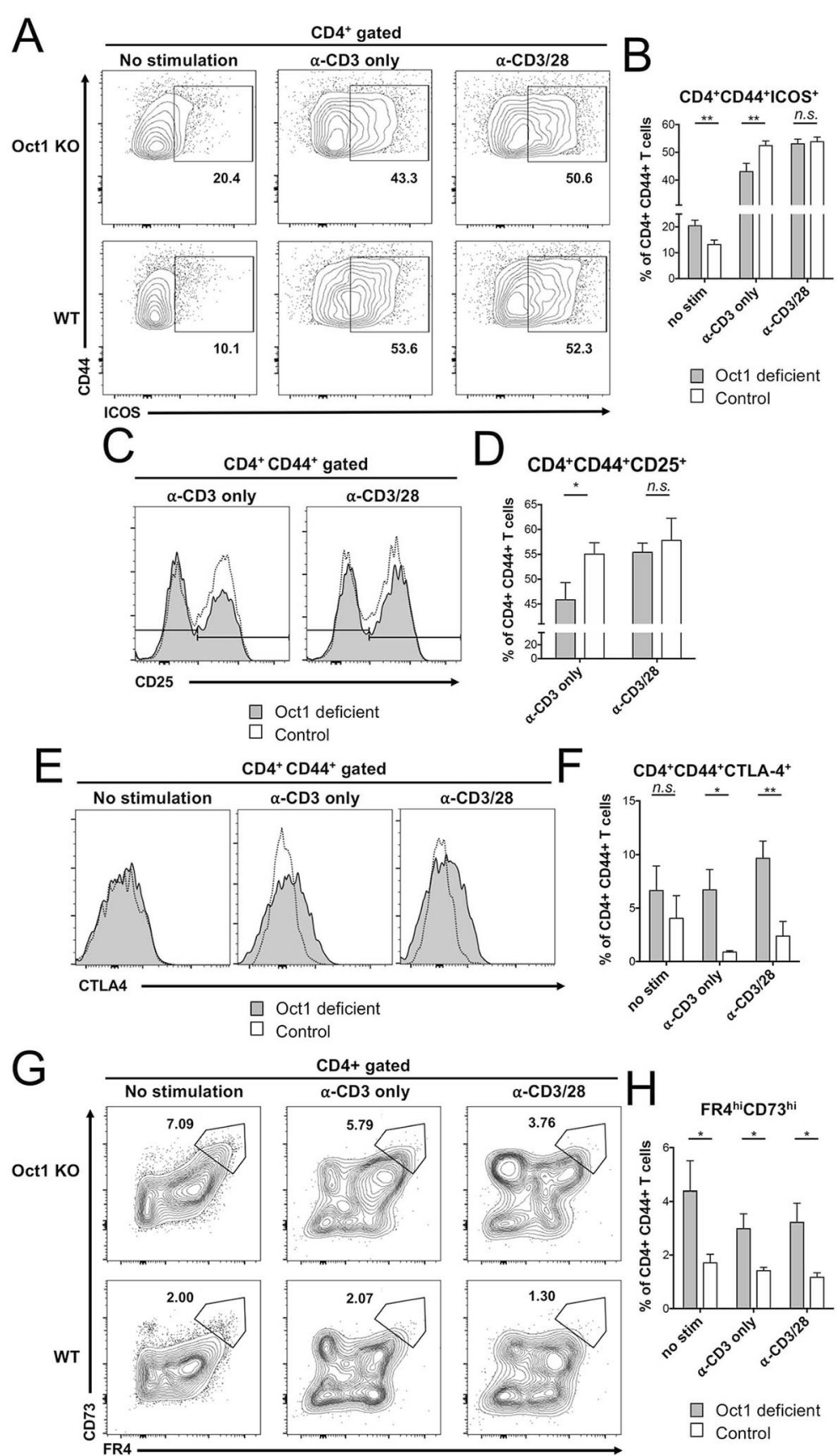

Fig. 2 In vitro stimulation of T cells lacking Oct1 results in decreased expression of markers associated with activation and increased expression of markers associated with anergy. a Oct1-deficient and control CD4 ${ }^{+} \mathrm{T}$ cells stimulated in vitro with indicated antibodies and analyzed by flow cytometry. Representative frequencies of ICOS-expressing CD4 $4^{+} \mathrm{CD} 44^{+}$cells are shown. b Quantification of cells independently purified from the spleens of three mice, with three technical culture replicates for each mouse. $\mathbf{c}$ Representative flow cytometry plots showing frequencies of CD25-expressing $\mathrm{CD}^{+} \mathrm{CD}_{4} 4^{+}$cells in Oct1-deficient and control CD4 ${ }^{+} \mathrm{T}$ cells. $\mathbf{d}$ Quantification from three animals. e Representative expression of CTLA-4 in $\mathrm{CD}^{+} \mathrm{CD}_{4}^{+} \mathrm{T}$ cells is plotted as histograms for Oct1-deficient and control CD4 ${ }^{+} \mathrm{T}$ cells. $\mathbf{f} \mathrm{CTLA} 4^{+}$percentages from three animals, with three culture replicates per animal, are plotted. $\mathbf{g}$ Expression of FR4 and CD73 in Oct1-deficient and control CD4 ${ }^{+}$CD $44^{+}$cells. $\mathbf{h}$ Averaged percentages of $\mathrm{FR} 4^{\text {hi }} \mathrm{CD} 73^{\text {hi }} \mathrm{CD} 4^{+} \mathrm{CD} 44^{+}$cells are plotted

[37], was increased by Oct1 loss in both anergic and full activation conditions (Fig. 2e, f). Similarly, FR4/CD73 double-positive cell frequencies were increased in Oct1- deficient cells compared to control cells in all conditions (Fig. 2g, h). CD $4^{+} \mathrm{CD} 44^{+} \mathrm{FR} 4{ }^{\mathrm{hi}} \mathrm{CD} 73^{\text {hi }}$ cells are associated with anergy [30, 38]. Frequencies of IFNY or IL-17 
producing cells in Th1 or Th17 differentiating culture conditions were also measured to investigate if Oct1 loss affects cytokine expression levels. No differences were observed after 5 days of stimulation with $\mathrm{MOG}_{35-55}$ peptide (data not shown). Thus, in vitro stimulation of $\mathrm{T}$ cells lacking Oct1 results in decreased expression of surface proteins associated with activation and increased expression of proteins associated with anergy.

The above findings suggest that targeting Oct1 could be a viable therapeutic strategy for MS. Prior findings using acute infection with the model pathogen LCMV indicate that Oct1 in $\mathrm{T}$ cells is dispensable for pathogen response and clearance, but necessary for robust memory recall responses [4]. However, the role of Oct1 in neuroinflammation caused by neurotropic viruses has not been tested. Significantly increased pathology in the case of JHMV would suggest that targeting Oct1 directly as a treatment for autoimmunity will result in unwanted side effects. To determine whether Oct1 mediates disease severity in viral-induced encephalomyelitis, we studied responses to JHMV. JHMV is a glial-tropic coronavirus and well-accepted model of viral-induced encephalomyelitis and immune-mediated demyelination [39-41]. Intracranial inoculation of C57BL/6 mice with JHMV typically results in acute encephalomyelitis, immune-mediated demyelination, and hind limb paralysis. $\mathrm{T}$ cell responses are critical for controlling JHMV replication within the CNS [42]. Age-matched Oct $f^{f l / f l}$ and CD4-Cre; Oct ${ }^{f l / f l}$ mice were intracranially (i.c.) inoculated with JHMV (200 PFU), and the severity of clinical disease and survival were monitored. JHMV-infected CD4-Cre;Oct ${ }^{f l f l}$ mice demonstrated no differences in clinical disease severity out to 21 days (Fig. 3a). Viral titers in the brains of JHMV-infected CD4-Cre;Oct ${ }^{f l / f l}$ compared to control mice were studied at defined times p.i. Although viral titers were elevated in the CNS at day 7 p.i. in CD4-Cre;Oct $1^{f l f l}$ mice compared to control animals, by day 21 , p.i. viral titers were below the level of detection ( $100 \mathrm{PFU} / \mathrm{g}$ tissue) in both groups (Fig. 3b). This result indicates that viral clearance is intact in Oct1 $\mathrm{T}$ cell-deficient mice. Supporting these findings, we observed similar degrees of demyelination at peak disease (day 12 p.i.) and endpoint (day 21 p.i., Fig. 3c, d). Numbers of infiltrating $\mathrm{CD}^{+}$(Fig. $4 \mathrm{a}, \mathrm{b}$ ) or $\mathrm{CD}^{+} \mathrm{T}$ cells (Fig. 4c, d) in CD4-Cre;Oct fllfl mice compared to control mice were similar. Furthermore, using tetramer staining [19-21], we observed no significant differences in virus-specific $\mathrm{CD}^{+}{ }^{+} \mathrm{T}$ cells (Fig. 4e, f) or $\mathrm{CD}^{+} \mathrm{T}$ cells (Fig. 4g, h). There was also no difference in the percentage of $\mathrm{CD} 25^{+}$cells or macrophage accumulation within the CNS of JHMV-infected mice at any time point (data not shown). We studied proinflammatory cytokine expression in CNS T cells from animals euthanized 21 days p.i. We did not observe significant levels of IL-17

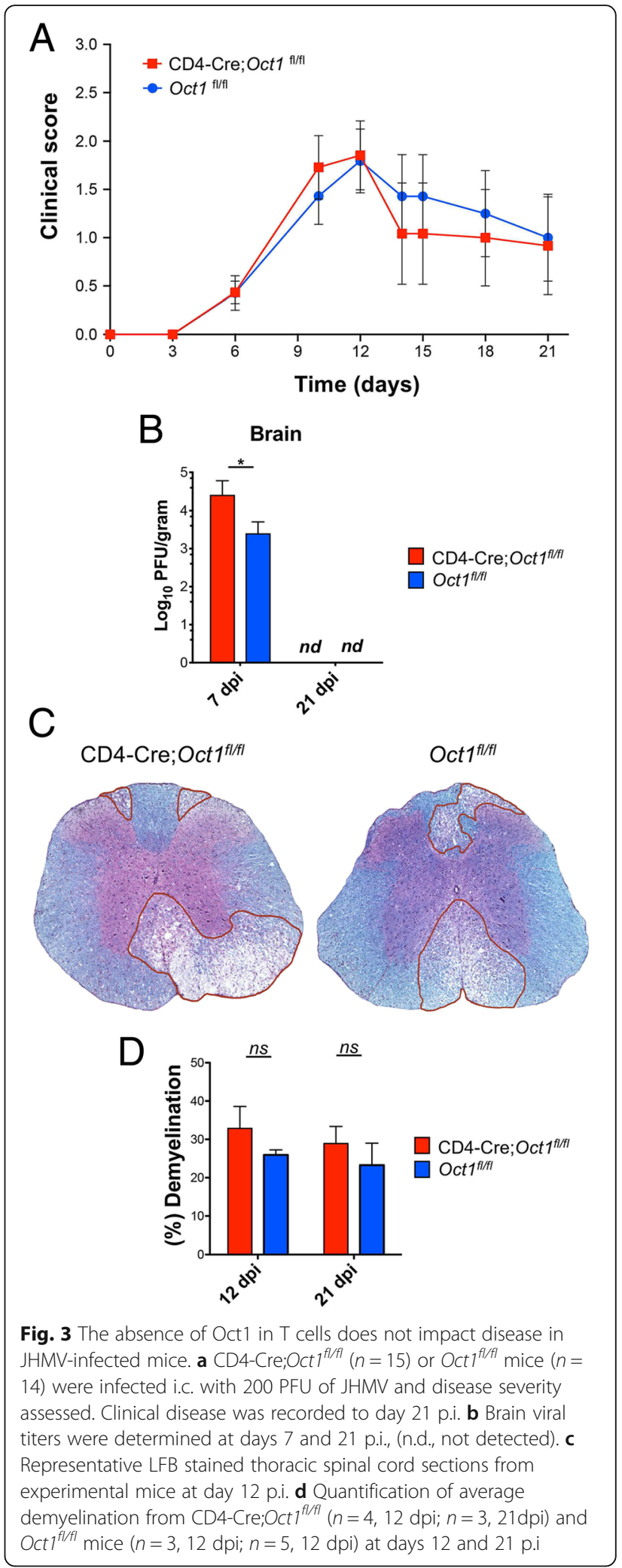




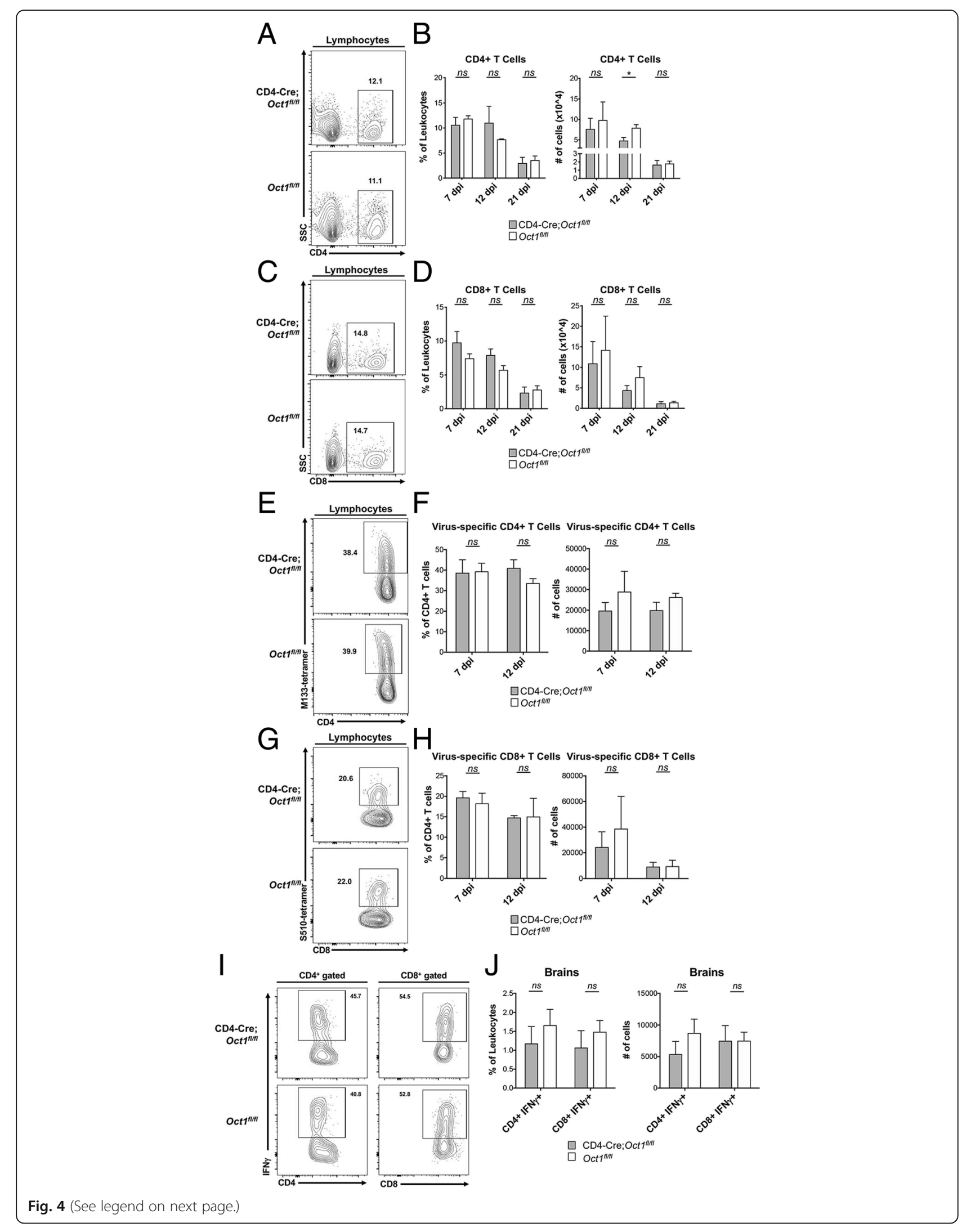




\section{(See figure on previous page.)}

Fig. 4 Normal immune responses in Oct1 T cell-deficient mice during JHMV infection. a CD4-Cre;Oct ff/flf or Oct $7^{f / f l}$ mice were infected i.c. with 200 PFU of JHMV and sacrificed at days $7(n=8), 12(n=4-5)$, and $21(n=6)$ p.i. to assess T cell infiltration into the brain. Representative flow analysis depicting $C D 4^{+} T$ cell infiltration into brains of mice at day 7 p.i. b Quantification of $C D 4^{+} T$ cells as shown by calculating both frequencies and numbers of isolated cells. $\mathbf{c}$ Representative flow analysis depicting $C D 8^{+} T$ cell infiltration into brains of mice at day 7 p.i. $\mathbf{d}$ Quantification of $\mathrm{CD}^{+} \mathrm{T}$ cells as shown by calculating both frequencies and numbers of isolated cells. e Representative M133-147 tetramer staining of $\mathrm{CD}^{+} \mathrm{T}$ cells from brains of JHMV-infected experimental mice. $\mathbf{f}$ Quantification of frequency and numbers of M133-147 tetramer CD4 ${ }^{+}$ T cells from experimental groups. $\mathbf{g}$ Representative S510-518 tetramer staining of CD8 ${ }^{+}$T cells from brains of JHMV-infected experimental mice. $\mathbf{h}$ Quantification of frequency and numbers of M133-147 tetramer CD4 ${ }^{+} \mathrm{T}$ cells from experimental groups. Data presented are derived from two

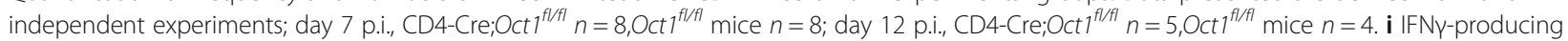
$\mathrm{CD}^{+}$(left panel) and CD8 ${ }^{+}$(right panel) CNS-infiltrating T cell percentages are shown for representative animals. $\mathbf{j}$ Averaged frequencies (left panel) and total cell numbers (right panel) of $\mathrm{CD} 4^{+}$and $\mathrm{CD} 8^{+}$cells analyzed as in $\mathbf{b} . \mathrm{N}=6$ for each group

expression (not shown), consistent with prior findings that Th17 cells do not play a prominent role in this model $[43,44]$. IFNy-expressing cells were present; however, we observed no significant differences in either percentage or numbers, or the degree of IFN $\gamma$ production (Fig. 4i, j). Together, these data suggest that Oct1 loss in $\mathrm{T}$ cells does not impact neurologic disease or immunemediated demyelination or $\mathrm{T}$ cell functionality in response to JHMV infection of the CNS.

\section{Discussion}

Here, we show that expression of the transcription factor Oct1 in $\mathrm{T}$ cells promotes CNS autoimmunity using MOG-EAE models, but only minimally participates in CNS anti-viral immunity. These results suggest that targeting Oct1, and its associated activities and pathways, could be used to treat autoimmunity while sparing viral pathogen-directed immune function.

Oct1 mechanisms of transcription regulation have been studied in $\mathrm{CD}^{+} \mathrm{T}$ cells $[4,8]$. Direct target genes include Il2, Ifng, Csf2 (Gmcsf), Icos, and Ctla4. However, unlike NF-AT or AP-1, Oct1 is dispensable for the baseline activity of these genes. Stimulation of primary $\mathrm{CD}_{4}^{+}$Oct1deficient naïve $\mathrm{T}$ cells results in normal levels and induction kinetics of the key T cell effector cytokine IL-2 [4, 8]. The normal $\mathrm{T}$ cell development and response to initial stimulation forms part of a potential "therapeutic window" in which targeting Oct1 and its associated pathways could be used to treat autoimmune responses with minimal side effects. Instead, Oct1 target genes show severely defective expression (100-fold or more) upon a second encounter with antigen and co-stimulatory signals $[4,8]$. In vivo, $\mathrm{CD}^{+}{ }^{+} \mathrm{T}$ cells lacking Oct1 mount a normal response to the acute viral pathogen LCMV, but fail to form memory cells in appreciable numbers. Those memory cells that are formed are defective in pathogen recall responses [4]. Memory cells are the most prone to making proinflammatory cytokines, and memory or memory-like cells can underlie autoimmunity, even in cases of persistent selfantigen exposure [5-7]. These findings, and the strong associations between human polymorphisms in binding sites for Oct1 and predisposition for autoimmune disease including MS [11-14], suggested a possible role for Oct1 in promoting MS.

MOG-EAE is an established model of MS, driven by inoculation with autoantigen in the presence of proinflammatory signals. Using this model, we showed that loss of Oct1 in $\mathrm{T}$ cells protects animals from clinical symptoms of EAE. This protection was associated with decreased CLN lymphadenopathy and proinflammatory cytokine expression, as well as decreased CNS T cell infiltration and cytokine expression.

$\mathrm{T}$ cell tolerance can be induced centrally, through thymic selection, or peripherally, due to the activity of induced Tregs or induction of anergy $[28,45]$. We found that stimulation of $\mathrm{CD}^{+}{ }^{+} \mathrm{T}$ cells lacking Oct1 with $\mathrm{CD} 3$ alone, to mimic TCR stimulation in the absence of costimulatory signals, significantly increased signs of anergy compared to control Oct1-sufficient cells. Decreased ICOS and CD25 levels were observed in Oct1-deficient cells in the absence of co-stimulation, whereas no differences were observed with co-stimulation. ICOS is a costimulatory molecule expressed by activated $\mathrm{T}$ cells with an important but complex role in the induction of $\mathrm{T}$ cell anergy in vitro and the development of autoimmunity in vivo [32-34]. Blocking ICOS during antigen priming promotes EAE, whereas blocking ICOS later in the disease course is protective [33, 35]. Interestingly, in addition to the decreased ICOS levels observed upon anergic stimulation, we found that unstimulated $\mathrm{CD} 4^{+} \mathrm{T}$ cells lacking Oct1 expressed baseline ICOS at higher levels. Both observations are therefore consistent with the observed protection in EAE models. Oct1-deficient cells also showed higher levels of the inhibitory receptor CTLA-4 and the anergic markers CD73 and FR4.

Our findings also reveal that Oct1 is dispensable for clinical responses to JHMV-induced neurologic disease, as clinical scores and demyelination were superimposable in this model. Expression of Oct1 accelerated but was not necessary for effective viral control. However, total and antiviral T cell numbers, cytokine expression, and macrophage recruitment were broadly unaffected. Examples include $\mathrm{T}$ cell percentages as well as numbers of cytokineexpressing cells and regulatory $\mathrm{T}$ cells. 


\section{Conclusion}

Collectively, these results indicate that while Oct1 loss has only modest effects on viral-induced inflammation, it profoundly improves responses to autoantigendriven disease. These results suggest that targeting Oct1 and its associated upstream and downstream pathways (such as the cofactor OCA-B) may be of therapeutic benefit in autoimmunity while sparing viral pathogen-directed immune function. Additional work will be required to identify which components of this pathway are potentially targetable.

\section{Additional file}

Additional file 1: Figure S1 IL-10 expression is unchanged in Oct1deficient T cells expressing decreased levels of CD25. Cells were prepared identically to Fig. 2. (JPG $239 \mathrm{~kb}$ )

\section{Abbreviations}

CFA: Complete Freund's adjuvant; CLNs: Cervical lymph nodes; CNS: Central nervous system; EAE: Experimental autoimmune encephalomyelitis; HBSS: Hank's balanced salt solution; i.c: Intracranial; i.p: Intraperitoneal; ICOS: Inducible T cell costimulator; JHMV: JHM strain of mouse hepatitis virus; LFB: Luxol fast blue; MOG: Myosin oligodendrocyte protein; MS: Multiple sclerosis; OCT: Optimum cutting temperature; p.i: Post-infection; PFU: Plaqueforming units; PT: Bordetella pertussis toxin; Treg: T regulatory cell

\section{Acknowledgements}

We thank T. Hanley, E. Hughes and J. Jafek for critical reading of the manuscript and V. Mangale for assistance with CNS cell isolation.

\section{Authors' contributions}

TEL and DT conceived the study and designed experiments, supervised the study, and provided administrative, technical, and material support. HK, LD, $C W$, and $J\lrcorner$ acquired and interpreted the data. All authors were involved in the writing, reviewing, and revising the manuscript. All authors read and approved the final manuscript.

\section{Funding}

This study was supported by an AAl graduate fellowship to HK, a National MS Society Postdoctoral Fellowship (FG 201050-A-1) to LD, grants from the NIH (R01NS041249) and Collaborative MS Research Center (CA-1607-25040) awarded to TEL, and endowed chair (Watkins Endowed Chair), a grant from the Praespero Foundation and an NIH grant R01Al100873 awarded to DT. TEL was also supported by donations from the Ray \& Tye Noorda Foundation and the McCarthey Family Foundation.

\section{Availability of data and materials}

Please contact the author for data requests.

\section{Ethics approval and consent to participate}

All experiments were reviewed, approved, and conducted in compliance with the University of Utah's Institutional Animal Care and Use Committee and the NIH Guide for Care and Use of Laboratory Animals guidelines.

\section{Consent for publication}

Not applicable

\section{Competing interests}

The authors declare that they have no competing interests.

\section{Author details}

${ }^{1}$ Department of Pathology, University of Utah School of Medicine, Salt Lake City, UT 84112, USA. ${ }^{2}$ Huntsman Cancer Institute, University of Utah School of Medicine, Salt Lake City, UT 84112, USA.
Received: 13 February 2019 Accepted: 17 June 2019

Published online: 03 July 2019

\section{References}

1. Steinman L. Immunology of relapse and remission in multiple sclerosis. Annu Rev Immunol. 2014;32:257-81.

2. Rumble JM, Huber AK, Krishnamoorthy G, Srinivasan A, Giles DA, Zhang X et al. Neutrophil-related factors as biomarkers in EAE and MS. J Exp Med. 2015;212:23-35.

3. Patsopoulos NA. Genetics of multiple sclerosis: an overview and new directions. Cold Spring Harb Perspect Med. 2018:8:a028951.

4. Shakya A, Goren A, Shalek A, German CN, Snook J, Kuchroo VK, et al. Oct1 and OCA-B are selectively required for CD4 memory T cell function. J Exp Med. 2015;212:2115-31.

5. Kawakami N, Odoardi F, Ziemssen T, Bradl M, Ritter T, Neuhaus O, et al. Autoimmune CD4+ T cell memory: lifelong persistence of encephalitogenic T cell clones in healthy immune repertoires. J Immunol. 2005;175:69-81.

6. Chee J, Ko H-J, Skowera A, Jhala G, Catterall T, Graham KL, et al. Effectormemory $T$ cells develop in islets and report islet pathology in type 1 diabetes. J Immunol. 2014;192:572-80.

7. Yeo L, Woodwyk A, Sood S, Lorenc A, Eichmann M, Pujol-Autonell I, et al. Autoreactive T effector memory differentiation mirrors $\beta$ cell function in type 1 diabetes. J Clin Invest. 2018;128:3460-74.

8. Shakya A, Kang J, Chumley J, Williams MA, Tantin D. Oct1 is a switchable, bipotential stabilizer of repressed and inducible transcriptional states. J Biol Chem. 2011:286:450-9.

9. Kim LK, Esplugues E, Zorca CE, Parisi F, Kluger Y, Kim TH, et al. Oct-1 regulates IL-17 expression by directing interchromosomal associations in conjunction with CTCF in T cells. Mol Cell. 2014;54:56-66.

10. Yosef N, Shalek AK, Gaublomme JT, Jin H, Lee Y, Awasthi A, et al. Dynamic regulatory network controlling $\mathrm{TH} 17$ cell differentiation. Nature. 2013:496:461-8.

11. Maurano MT, Humbert R, Rynes E, Thurman RE, Haugen E, Wang H, et al. Systematic localization of common disease-associated variation in regulatory DNA. Science. 2012;337:1190-5.

12. Farh KK-H, Marson A, Zhu J, Kleinewietfeld M, Housley WJ, Beik S, et al. Genetic and epigenetic fine mapping of causal autoimmune disease variants. Nature. 2015;518:337-43.

13. van Heel DA, Udalova IA, De Silva AP, McGovern DP, Kinouchi Y, Hull J, et al. Inflammatory bowel disease is associated with a TNF polymorphism that affects an interaction between the OCT1 and NF(-kappa)B transcription factors. Hum Mol Genet. 2002;11:1281-9.

14. Graham DSC, Wong AK, McHugh NJ, Whittaker JC, Vyse TJ. Evidence for unique association signals in SLE at the CD28-CTLA4-ICOS locus in a family-based study. Hum Mol Genet. 2006;15:3195-205.

15. Grist JJ, Marro BS, Skinner DD, Syage AR, Worne C, Doty DJ, et al. Induced CNS expression of CXCL1 augments neurologic disease in a murine model of multiple sclerosis via enhanced neutrophil recruitment. Eur J Immunol. 2018;48:1199-210

16. Stiles LN, Hardison JL, Schaumburg CS, Whitman LM, Lane TE. T cell antiviral effector function is not dependent on CXCL10 following murine coronavirus infection. J Immunol. 2006:177:8372-80.

17. Stiles LN, Hosking MP, Edwards RA, Strieter RM, Lane TE. Differential roles for CXCR3 in CD4+ and CD8+ T cell trafficking following viral infection of the CNS. Eur J Immunol. 2006;36:613-22.

18. Stiles LN, Liu MT, Kane JAC, Lane TE. CXCL10 and trafficking of virusspecific $T$ cells during coronavirus-induced demyelination. Autoimmunity. 2009:42:484-91.

19. Dickey LL, Worne CL, Glover JL, Lane TE, O'Connell RM. MicroRNA155 enhances $T$ cell trafficking and antiviral effector function in a model of coronavirus-induced neurologic disease. J Neuroinflammation. 2016;13:240.

20. Marro BS, Grist JJ, Lane TE. Inducible expression of CXCL1 within the central nervous system amplifies viral-induced demyelination. J Immunol. 2016:196:1855-64.

21. Blanc CA, Rosen H, Lane TE. FTY720 (fingolimod) modulates the severity of viralinduced encephalomyelitis and demyelination. J Neuroinflammation. 2014;11:138

22. Bittner S, Afzali AM, Wiendl H, Meuth SG. Myelin oligodendrocyte glycoprotein (MOG35-55) induced experimental autoimmune encephalomyelitis EAE) in C57BL/6 mice. J Vis Exp. 2014;e51275. 
23. Goverman J. Autoimmune T cell responses in the central nervous system. Nat Rev Immunol. 2009;9:393-407.

24. Segal BM, Shevach EM. IL-12 unmasks latent autoimmune disease in resistant mice. J Exp Med. 1996;184:771-5.

25. Langrish CL, Chen Y, Blumenschein WM, Mattson J, Basham B, Sedgwick JD, et al. IL-23 drives a pathogenic T cell population that induces autoimmune inflammation. J Exp Med. 2005;201:233-40.

26. Goverman J, Perchellet A, Huseby ES. The role of CD8(+) T cells in multiple sclerosis and its animal models. Curr Drug Targets Inflamm Allergy. 2005;4:239-45.

27. Friese MA, Fugger L. Autoreactive CD8+ T cells in multiple sclerosis: a new target for therapy? Brain. 2005;128:1747-63.

28. Kearney ER, Pape KA, Loh DY, Jenkins MK. Visualization of peptidespecific T cell immunity and peripheral tolerance induction in vivo. Immunity. 1994;1:327-39.

29. Vanasek TL, Khoruts A, Zell T, Mueller DL. Antagonistic roles for CTLA-4 and the mammalian target of rapamycin in the regulation of clonal anergy: enhanced cell cycle progression promotes recall antigen responsiveness. J Immunol. 2001;167:5636-44.

30. Kalekar LA, Schmiel SE, Nandiwada SL, Lam WY, Barsness LO, Zhang N, et al. $\mathrm{CD} 4(+) T$ cell anergy prevents autoimmunity and generates regulatory $T$ cell precursors. Nat Immunol. 2016:17:304-14.

31. Chai JG, Lechler RI. Immobilized anti-CD3 mAb induces anergy in murine naive and memory CD4+ T cells in vitro. Int Immunol. 1997:9:935-44.

32. Tuettenberg A, Huter E, Hubo M, Horn J, Knop J, Grimbacher B, et al. The role of ICOS in directing T cell responses: ICOS-dependent induction of T cell anergy by tolerogenic dendritic cells. J Immunol. 2009;182:3349-56.

33. Dong C, Juedes AE, Temann UA, Shresta S, Allison JP, Ruddle NH, et al. ICOS co-stimulatory receptor is essential for T-cell activation and function. Nature. 2001;409:97-101.

34. Dong C, Nurieva RI. Regulation of immune and autoimmune responses by ICOS. J Autoimmun. 2003;21:255-60.

35. Rottman JB, Smith T, Tonra JR, Ganley K, Bloom T, Silva R, et al. The costimulatory molecule ICOS plays an important role in the immunopathogenesis of EAE. Nat Immunol. 2001;2:605-11.

36. Caruso A, Licenziati S, Corulli M, Canaris AD, De Francesco MA, Fiorentini S, et al. Flow cytometric analysis of activation markers on stimulated T cells and their correlation with cell proliferation. Cytometry. 1997;27:71-6.

37. Greenwald RJ, Boussiotis VA, Lorsbach RB, Abbas AK, Sharpe AH. CTLA-4 regulates induction of anergy in vivo. Immunity. 2001;14:145-55.

38. Martinez RJ, Zhang N, Thomas SR, Nandiwada SL, Jenkins MK, Binstadt $B A$, et al. Arthritogenic self-reactive CD4+ $T$ cells acquire an FR4hiCD73hi anergic state in the presence of Foxp3+ regulatory T cells. J Immunol. 2012:188:170-81.

39. Lane TE, Hosking MP. The pathogenesis of murine coronavirus infection of the central nervous system. Crit Rev Immunol. 2010;30:119-30.

40. Bergmann CC, Lane TE, Stohlman SA. Coronavirus infection of the central nervous system: host-virus stand-off. Nat Rev Microbiol. 2006:4:121-32.

41. Liu MT, Lane TE. Chemokine expression and viral infection of the central nervous system: regulation of host defense and neuropathology. Immunol Res. 2001;24:111-9.

42. Williamson JS, Stohlman SA. Effective clearance of mouse hepatitis virus from the central nervous system requires both $C D 4+$ and $C D 8+T$ cells. J Virol. 1990;64:4589-92.

43. Held KS, Glass WG, Orlovsky YI, Shamberger KA, Petley TD, Branigan PJ, et al. Generation of a protective T-cell response following coronavirus infection of the central nervous system is not dependent on IL-12/23 signaling. Viral Immunol. 2008;21:173-88.

44. Kapil P, Atkinson R, Ramakrishna C, Cua DJ, Bergmann CC, Stohlman SA Interleukin-12 (IL-12), but not IL-23, deficiency ameliorates viral encephalitis without affecting viral control. J Virol. 2009:83:5978-86.

45. Xing Y, Hogquist KA. T-cell tolerance: central and peripheral. Cold Spring Harb Perspect Biol. 2012:4:a006957.

\section{Publisher's Note}

Springer Nature remains neutral with regard to jurisdictional claims in published maps and institutional affiliations.

\section{Ready to submit your research? Choose BMC and benefit from:}

- fast, convenient online submission

- thorough peer review by experienced researchers in your field

- rapid publication on acceptance

- support for research data, including large and complex data types

- gold Open Access which fosters wider collaboration and increased citations

- maximum visibility for your research: over $100 \mathrm{M}$ website views per year

At BMC, research is always in progress.

Learn more biomedcentral.com/submissions 